\title{
РЕАЛИЗАЦИЯ НАЦИОНАЛЬНЫХ ИДЕЙ ЧЕРЕЗ ГОСУДАРСТВЕННЫЕ ПРОГРАММЫ
}

\section{(c) 2021 Соколов Алексей Вячеславович}

магистрант, факультет «Социальных наук и массовых коммуникаций», Департамент политологии Финансовый университет при Правительстве Российской Федерации, Россия, Москва

E-mail: sokol096@mail.ru

\section{(c) 2021 Зубков Александр Данилович}

доцент кафедры анализа и прогнозирования

Московский государственный стоматологический университет им. А. И.Евдокимова, Россия, Москва

Статья посвящена актуальным вопросам поиска национальных идей через реализацию национальных программ. Выявлены проблемы в реализации национальных проектов. Несмотря на степень изученности вопросов, некоторые проблемы теоретических и практических характеристик, таких, как поиск содержания и путей реализации национальной идеи в России 21 века, остаются нерешенными, и требуют дальнейшего исследования в связи с изменением политической и экономической ситуации на современном этапе.

Ключевые слова: Национальная идея, программа, проект, реализация программы, демография, федеральные программы, «майские указы»

Национальная идея - одно из немногих явлений, понимаемое в ценностном смысле, но находящее свое непосредственное выражение в поле практической политики. В связи с чем, национальная идея представляется как ценность, способная цементировать основы стабильности и безопасности государства, имеющая исторические традиции, укорененные в сознании народа.

В настоящее время происходят кардинальные перемены во всех сферах жизни российского общества, значительно корректирующие научные представления о нем, вопрос сущности государства, его назначения и места. В связи с этим, поиск концепции национальной идеи продолжается в наше время. Поиск оптимальной концепции государства с помощью осваивания интеллектуального потенциала «западной» и «восточной» цивилизации, «заимствования лучшего» недостаточно для решения проблем современного российского государства. В современном мире суверенитет государств, в частности России, подвержен внешним угрозам. Данными угрозами являются пандемия COVID-19, агрессивная политика стран ЕС и США в отношении Российской Федерации с помощью применения санкций. Внутри страны действия внесистемной оппозиции, также являются угрозой для действующего режима власти.
Переход к рыночной экономике способствовал национальному самоопределению, который на сегодняшний день является одним из важных направлений в развитии страны. Каждая страна самостоятельно занимается формированием национального самоопределения. Становление рыночной экономики для Российской Федерации после распада СССР привело к необходимости в формировании самоидентификации. Данный процесс представлял собой достаточно сложную трансформацию, поскольку СССР являлся единой национальной системой, которая была образована за долгое время.

В 90-е гг. был принят определенный ряд законов, который был нацелен на становление Российской национальной политики. В их число можно включить концепцию государственной национальной политики от 1996 г., а также ряд законов: «Об общественных объединениях», «О языках народов РФ», «О национальнокультурной автономии», и многие другие документы [1, с. 12].

В последние годы в России был принят ряд национальных программ, определяющих дальнейшее развитие государства. Эти программы можно рассматривать, как инструмент воплощения национальных идей в России.

О национальных проектах начали задумываться еще в 2018 г., их необходимость предпола- 
гала охват всевозможных сфер жизни населения. В 2018 г., В.В, Путин издал указы, которые включали показатели, которые смогли бы вывести страну на высокий уровень. К примеру, увеличение продолжительности жизни к 2030 г. до 70 лет. Данный запуск проектов можно было наблюдать в 2019 г., они были рассчитаны до 2024 г., однако уже в июле 2020 г., в связи с коронавирусной инфекцией пришлось принять решение, отложить достижение некоторых показателей до 2030 г.

Координационная деятельность по формированию и дальнейшему осуществлению национальных проектов стране сосредоточена в работе Совета по стратегическому развитию и национальным проектам при Президенте Российской Федерации. Развитием проектов трех программ непосредственно занимаются вице-премьеры.

Одними из наиболее важных проектов на сегодняшний день можно назвать такие проекты как «Здравоохранение», «Образование», «Демография» и «Наука». В целом на реализацию данных проектов было выделено из государственного бюджета 6,3 трлн. руб. Ответственным за исполнение данных проектов назначена Татьяна Голикова.

Реализация нацпроектов в 2020 г. представлена в таблице 1 [5].

Один из основных национальных проектов - «Образование», который предполагает три приоритетных направления: доступность образования на протяжении жизни, профилактика и коррекция образовательной неуспешности, достижение современного качества. Образова- ние является ключевым механизмом не только сохранения, но и развития человеческого потенциала, который, в свою очередь, обеспечивает социально-политическую устойчивость, преемственность культуры, производительность труда и научно-технологическое развитие [5].

Формирование эффективной системы дополнительного образования особенно актуально в условиях ускоряющихся изменений в структуре рынков труда и роста нелинейных профессиональных траекторий, при которых работники меняют сферу деятельности несколько раз в течение карьеры. Так, согласно данным исследования сервиса «Работа.ру» и портала «Рамблер», большинство россиян (64\%) не работают по профессии, которую получили в училищах и вузах. Причины такой ситуации разные - низкие доходы на работе по специальности, усталость от полученной профессии, сложности с поиском работы по специальности, иные жизненные обстоятельства, связанные с переездом, браком и т.д. Важно и то, что большинство респондентов (76\%) отметили, что им удалось обучиться новой профессии самостоятельно. В подобных условиях эффективная политика расширения и повышения доступности программ дополнительного профессионального образования может быть востребована широкими слоями взрослого населения, адаптирующимися под изменения на рынке труда.

Следующим национальным проектом, который проанализируем, является «Демография».

В национальном проекте «Демография» уточнены национальные цели развития с уче-

Таблиц̧а 1. Реализация нацпроектов в 2020 г.

\begin{tabular}{|l|c|c|c|}
\hline \multicolumn{1}{|c|}{ Нацпроект } & Запланировано & Факт. расходов & Исполнение. \\
на 2020 г., млн.p. & за 2020 г., млн.p. & 2020 г., \% \\
\hline Демография & 520,2 & 496,791 & 95,5 \\
\hline Здравоохранение & 160,3 & 157,094 & 98 \\
\hline Образование & 106,1 & 96,551 & 91 \\
\hline Жилье и городская среда & 105,3 & 98,7714 & 93,8 \\
\hline Экология & 57,0 & 37,791 & 66,3 \\
\hline Безопасные и качественные автомобильные дороги & 129,7 & 125,9387 & 97,1 \\
\hline Производительность труда и поддержка занятости & 7,1 & 6,1841 & 87,1 \\
\hline Наука & 37,0 & 36,667 & 99,1 \\
\hline Цифровая экономика & 108,0 & 79,164 & 73,3 \\
\hline Культура & 14,2 & 14,058 & 99 \\
\hline Малое и среднее предпринимательство & 60,6 & 56,4186 & 93,1 \\
\hline Международная кооперация и экспорт & 86,2 & 76,8042 & 89,1 \\
\hline Комплексный план & 331,2 & 291,456 & 88 \\
\hline
\end{tabular}


том изменений в экономической и социальной жизни российского общества, обусловленных экономическими шоками, политическими конфликтами и пандемией коронавируса. Реализация стратегических целей должна обеспечить рост численности населения, повышение уровня жизни, создание условий для раскрытия таланта каждого человека.

Из-за пандемии коронавируса в 2020 г. процесс депопуляции усилился. Согласно данным Росстата, на 1 июня 2020 г. численность населения сократилась на 182,9 тыс. человек по сравнению с началом года. За аналогичный период предыдущего года постоянное население уменьшилось на 65,3 тыс. человек. Миграционный прирост составил 38,4 тыс. человек и компенсировал естественную убыль населения только на $17,4 \%$. По среднему варианту прогноза Росстата, выполненному до начала коронавирусной эпидемии, численность населения России в 2021 г. сократится примерно на 100 тыс. человек, а за период с 2021 по 2024 г. включительно - на 790 тыс. человек [3, с. 9].

Весна 2020 г. была отмечена активным выдвижением гипотез по поводу быстрых и коренных мутаций городского образа жизни в целом, которые произойдут как под влиянием уже состоявшейся вирусной атаки на крупные и крупнейшие города мира, так и в ожидании новых эпидемиологических угроз. Прогноз сводится к тому, что мир городов после коронавируса не изменится. Инфраструктура городов, в отличие от вируса, неспособна к быстрым мутациям. Соответственно, жители городов с невысокой плотностью населения и высоким значением LAS (процентная часть застроенной территории города, отводимая под улично-дорожную сеть) будут по-прежнему ездить в основном на автомобилях. В то же время жители городов с высокой плотностью населения и скромным значением LAS в подавляющей своей части будут по-прежнему пользоваться общественным транспортом, оставляя для автомобилей чуть большую, чем сегодня, процентную часть пассажирского спроса.

Рассматривая национальные проекты, мож- но выявить некоторые проблемы.

В некоторых проектах присутствует непрозрачность в расчетах, что может приводить к снижению эффективности их реализации. К примеру, если говорить о федеральном проекте «Борьба с онкологическими заболеваниями», можно заметить, что в целом на его реализацию планируется лишь 6\% от той суммы, которая была запланирована в 2020 г. Если анализировать разбивку по статьям реализации данного проекта, то можно увидеть, что большая часть (70\%) составляют затраты, связанные со статьей «Оказание медицинской помощи больным с онкологическими заболеваниями в соответствии с клиническими рекомендациями». В тоже время, наиболее точной информации о сумме предоставлении данных затрат найти не удалось. Это говорит о том, что нет возможности в отслеживании правильности составлении смет на ту или иную программу, входящую в национальный проект.

Следует также выделить и такую проблему, возникающую в реализации национальных проектов, как снижение темпов исполнения расходов, а это в свою очередь приводит к уменьшению темпов роста в реализации национальных проектов. К примеру, если анализировать 2020 г., то к концу года его уровень выполнения находился на отметке 91,4\%, при этом, если говорить об уровне исполнения бюджетных расходов - в $94,2 \%$. Все это свидетельствует о снижении исполнительской способности бюджетных расходов [4, с. 18].

Национальные проекты являются отражением тех национальных идей, которые преследует Российская Федерация на сегодняшний момент, и которые достаточно расширились в отличие от тех идеологических направлений, присутствовавших во времена Советского Союза. Проведенный анализ возможностей для устойчивого развития в новых экономических, политических и социальных условиях позволил прийти к выводу о том, что цели достигаются только при условии роста инвестиций в человеческий потенциал и создание условий для повышения его вклада в развитие.

\section{Библиографический список}

1. Балаев А.И. Влияние структуры бюджетных расходов на экономический рост в России//Экономическая политика.-2018.- Т. 13.- № 6.

2. аменских М., Иванова Н. Эффективность государственных расходов в России//Экономическая политика.2011. - № 1.- С. 176-192. 
3. Кудрин А.Л., Кнобель А. Ю. Бюджетная политика как источник экономического роста//Вопросы экономики.2017. - № 10.- С. 5-26.

4. Громов А.Д.Влияние государственных расходов на экономический рост//Научно-исследовательский финансовый институт. Финансовый журнал. - 2015. - № 4.- С. 62-71.

5. Национальные проекты: ожидания, результаты, перспективы // [Электронный ресурс] / Официальный сайт Эксперт РА. Режим доступа: https://raexpert.ru/researches/national_project_2020/\#part7 (дата обращения: 12.05.2021) 